\title{
Energy drinks: health risks and toxicity
}

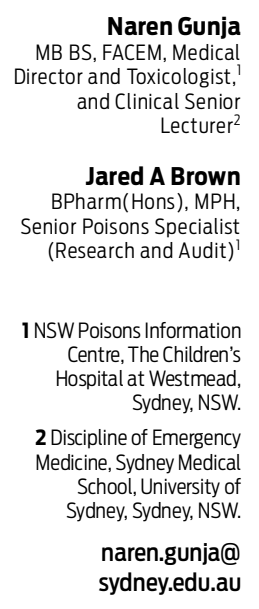

MJA 2012; 196: 46-49 doi: 10.5694/mjall.10838

\section{T}

he new millennium has ushered in a wave of synthetic, caffeinated high-energy drinks targeted at the youth market. Over the past 10 years, the consumption of caffeinated beverages intended to "energise" has increased significantly. Energy drinks were recently shown to comprise $20 \%$ of the total convenience store beverage market, with "Red Bull" and "V" accounting for over $97 \%$ of sales in this multimillion-dollar industry. ${ }^{1}$ Increasingly, toxicity from caffeine overdose is being reported to hospitals and poisons centres.

The main active constituents of energy drinks include varying amounts of caffeine, guarana extract, taurine and ginseng. Additional amino acids, vitamins and carbohydrates usually complete the list of purportedly beneficial ingredients. ${ }^{2}$ The intended effects of energy drinks are to provide sustenance and improve performance, concentration and endurance. Manufacturers pitch their product to athletes, students and people in professions that require sustained alertness. These drinks are also commonly consumed at dance parties, which require sustained energy for prolonged activity into late hours. In this setting, they may also be combined with alcohol and recreational drugs such as ecstasy (MDMA; 3,4-methylenedioxymethamphetamine) or other amphetamines. Young adults and adolescents are particularly attracted to energy drinks because of effective product marketing, peer influence and a lack of knowledge of the potential harmful effects. ${ }^{3-5}$ The high sugar content in caffeinated energy drinks is similar to other soft drinks and is known to contribute to obesity. ${ }^{6}$

Adverse reactions and toxicity from high-energy drinks stem primarily from their caffeine content. ${ }^{7}$ The sympathomimetic effects of high-dose caffeine mostly explain the symptoms and hospital presentations related to energy drinks. There is little published literature on the extent and epidemiology of this problem. Indeed, a recent literature review on the effects of energy drinks in children and adolescents found only eight case reports

\section{Abstract \\ Objectives: To describe the epidemiology and toxicity of caffeinated energy} drink exposures in Australia.

Design, setting and subjects: Retrospective observational study analysing data from calls regarding energy drink exposures recorded in the database of an Australian poisons information centre over 7 years to 2010.

Main outcome measures: Type of exposure; co-ingestants; symptoms reported; and reported hospitalisations.

Results: Callers reported 297 exposures to energy drinks, which showed an increasing annual trend from 12 in 2004 to 65 in 2010. Median age for the 217 subjects with recreational exposure was 17 years (interquartile ratio [IQR], 15-21; range, 11-60) and 57\% were male. One hundred recreational users co-ingested other substances, predominantly alcohol (50) or other caffeinated products (44). The number of energy drinks consumed in one session varied greatly (median, 5 units; IQR, 3-8; range, 1-80). Most subjects who reported recreational use reported experiencing symptoms (87\%). The most common symptoms were palpitations, agitation, tremor and gastrointestinal upset. Twenty-one subjects had signs of serious cardiac or neurological toxicity, including hallucinations, seizures, arrhythmias or cardiac ischaemia. At least 128 subjects ( 57 with no co-ingestants) required hospitalisation.

Conclusions: Reports of caffeine toxicity from energy drink consumption are increasing, particularly among adolescents, warranting review and regulation of the labelling and sale of these drinks. Educating adolescents and increasing the community's awareness of the hazards from energy drinks is of paramount importance.

on medical complications from energy drinks. ${ }^{8}$ Our study was undertaken to obtain an understanding of the scope of consumption-related issues and toxicity from caffeinated energy drinks in Australia by analysing data from calls to the NSW Poisons Information Centre (NSWPIC) - the largest centre of its type in Australia, taking about 110000 calls per year, which is $50 \%$ of all poisoning-related calls in the country.

\section{Methods}

We undertook a retrospective review at the NSWPIC. Data included calls providing advice to the general public and health professionals. Calls from New South Wales, Tasmania and the Australian Capital Territory are exclusively handled by NSWPIC from 6 am to midnight; an after-hours call-sharing system is in place with interstate poisons centres. Ethics approval was obtained from the human research ethics committee of the Children's Hospital at Westmead.

We searched the NSWPIC Microsoft Access database for calls relating to caffeinated energy drink ingestions in the 7-year period from January 2004 to December 2010. Our search strategy included "guarana", "caffeine", "ethanol", "food additives", "energy drink", "alcohol: other/ unknown", and "non-drug product: other/unknown". Due to the large number of "other/unknown" exposures, a filter was applied to find results with the name of any known Australian marketed energy drink or "caffeine" or "energy" in the free-text product name field. "Recreational" ingestion was defined as intentional ingestion for the purpose of gaining euphoria or other psychotropic effect. "Accidental paediatric" ingestion was defined as non-deliberate ingestion by a person under 18 years of age.

Finally, all the cases found from this search were subjected to manual review for inclusion and subsequent coding and verification of the reported type of exposure, co-ingestants, symptoms, dose, brand of drink, and the subject's age, sex and hospitalisation status. Symptoms and coding were reviewed separately by the authors. Discrepancies were discussed until agreement was achieved.

We used mean and SD to describe normally distributed data, and 

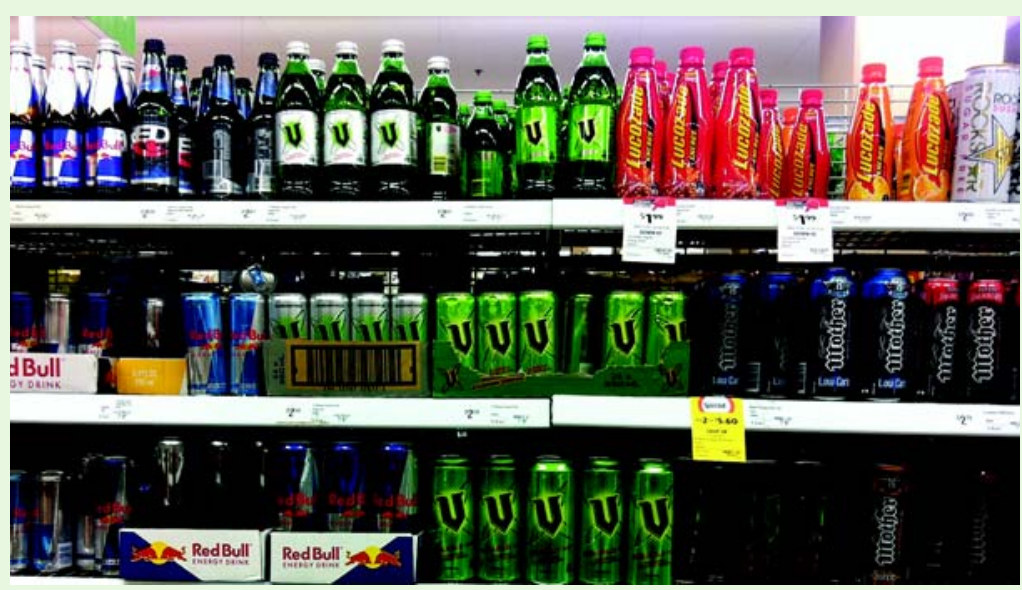

median and interquartile range (IQR) for non-parametric data. All statistical analyses were performed using SPSS, version 19.0 for Windows (SPSS Inc, Chicago, Ill, USA).

\section{Results}

Over the 7-year period that we examined, data for 297 calls related to caffeinated energy drink exposures were recorded. Call numbers increased from 12 in 2004 to 65 in 2010 (Box 1). The most common exposure type was recreational (217); other exposures were classified as accidental paediatric (62), deliberate self-poisoning as part of a polypharmacy overdose (16), allergic reaction (1) and paediatric lactational exposure (1). The brands of energy drinks to which subjects were most commonly exposed and their active ingredients are listed in Box 2 . Sixty per cent of calls were received between $5 \mathrm{pm}$ and $3 \mathrm{am}$.

\section{Recreational use}

Typically, recreational users were adolescents or young adults. Median age was 17 years (IQR, 15-21; range, 11$60)$, and $57 \%$ were male. The number of drinks consumed in one session varied greatly (median, 5 units; IQR, 3-8 units; range, 1-80 units). Coingestion of other substances was recorded for $46 \%$ of recreational users (Box 3). The most popular co-ingested substances were alcohol and other caffeine-containing products.

Commonly reported symptoms and their frequency are listed in Box 4. Symptoms were occasionally reported even at manufacturer-recommended amounts of energy drink consumption and were frequently reported with recreational use $(87 \% ; 188 / 217)$. The most commonly reported symptoms were related to gastrointestinal upset and sympathetic overdrive, as can be predicted for caffeine toxicity. Twentyone callers reported signs of serious toxicity such as hallucinations, seizures, and cardiac ischaemia. At least 128 people required emergency department (ED) attendance, 57 of whom had not co-ingested another substance. Of those attending an ED, 79 had self-presented and 49 had been referred by the NSWPIC for further management based on the clinical significance of their symptoms.

\section{Accidental paediatric ingestion}

Sixty-two children were reported to have accidentally ingested energy drinks (mean age, 38 months; SD, 24 months; range, 7-120 months). Of these, 14 had symptoms probably related to energy drink consumption - most commonly hyperactivity (Box 4) - and nine required assessment in hospital.

\section{Discussion}

Our study demonstrates the extent of the growing problem in Australia with energy drink consumption and toxicity, particularly among adolescents. Serious adverse effects and toxicity are seen with energy drinks containing variable amounts of caffeine. The phenomenon of mixing energy drinks with alcohol, stimulants and other coingestants is clearly occurring and is a serious concern.
1 Annual number of energy drink exposures reported to the NSW Poisons Information Centre, Jan 2004 - Dec 2010, by type of exposure

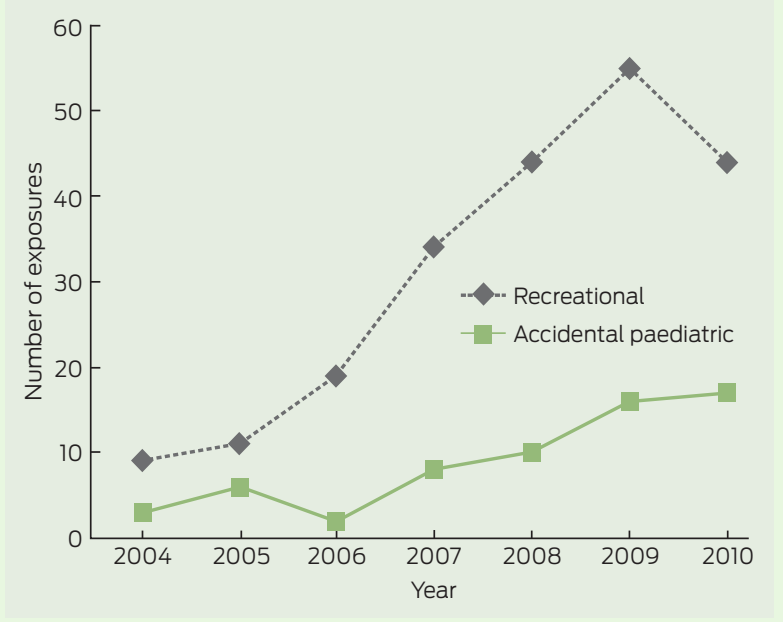

\begin{tabular}{|c|c|c|c|}
\hline Product & $\begin{array}{l}\text { Main ingredients, dose/ } \\
100 \mathrm{~mL}\end{array}$ & $\begin{array}{c}\text { Maximum } \\
\text { volume* }(\mathrm{mL})\end{array}$ & No. of calls \\
\hline Red Bull & $\begin{array}{l}\text { Caffeine, } 32 \mathrm{mg} \\
\text { Sugars, } 11 \mathrm{~g}\end{array}$ & 500 & 126 \\
\hline V & $\begin{array}{l}\text { Caffeine, } 32 \mathrm{mg} \\
\text { Guarana extract, } 120 \mathrm{mg}\end{array}$ & 500 & 68 \\
\hline Pulse & $\begin{array}{l}\text { Ethanol, } 7 \mathrm{~g} \\
\text { Caffeine, } 7 \mathrm{mg}\end{array}$ & 300 & 15 \\
\hline Mother & $\begin{array}{l}\text { Caffeine, } 32 \mathrm{mg} \\
\text { Sugars, } 10.5 \mathrm{~g}\end{array}$ & 500 & 25 \\
\hline RockStar & $\begin{array}{l}\text { Caffeine, } 32 \mathrm{mg} \\
\text { Guarana extract, } 10 \mathrm{mg} \\
\text { Ginseng extract, } 20 \mathrm{mg} \\
\text { Sugars, } 13 \mathrm{~g}\end{array}$ & 473 & 5 \\
\hline $\begin{array}{l}\text { Other/ } \\
\text { unknown }\end{array}$ & - & - & 58 \\
\hline Other caffein & e-containing products ( $\mathrm{fc}$ & r comparison) & \\
\hline Cola drinks & $\begin{array}{l}\text { Caffeine, approximately } \\
40 \mathrm{mg} \text { per can ( } 11 \mathrm{mg} \text { per } \\
100 \mathrm{~mL} \text { ) }\end{array}$ & - & nd \\
\hline Coffee & $\begin{array}{l}\text { Caffeine, approximately } \\
\text { 25-200 mg per cup }\end{array}$ & - & nd \\
\hline $\begin{array}{l}\text { No-Doz/No- } \\
\text { DozPlus }\end{array}$ & $\begin{array}{l}\text { Caffeine, } 100 \mathrm{mg} / \mathrm{tablet} \\
\text { (packs of } 24 \text { and 100) }\end{array}$ & - & 545 \\
\hline
\end{tabular}

In 2009, the energy drink industry spent nearly \$15 million on marketing alone in Australia. Value growth in the convenience sector had increased by $20 \%$ as compared with $10 \%$ for carbonated beverages on the whole. ${ }^{9}$ The target population for these types of drinks clearly includes adolescents and young adults, as well as professionals. ${ }^{10}$ Consumers are likely to be unaware of the variation in chemical composition and caffeine dosage in 
3 Recreational use of other substances with energy drinks $(n=217)$

\begin{tabular}{lc} 
Co-ingestant & $\begin{array}{c}\text { No. of } \\
\text { subjects }\end{array}$ \\
\hline None & 117 \\
One or more co-ingestant & 100 \\
Alcohol & 50 \\
Caffeine tablets & 34 \\
Ecstasy/amphetamines or & 15 \\
Other illicit stimulants & \\
Other caffeinated beverages & 10 \\
Other illicit substances & 3 \\
Other & 12
\end{tabular}

energy drinks, and with little or no warnings on products, the potential for overdose and poisoning remains ever-present.

A typical can of energy drink may contain up to $300 \mathrm{mg}$ of caffeine, from added caffeine and natural sources such as guarana. ${ }^{11}$ Guarana, an extract from the plant Paullinia cupana, contains caffeine, theobromine and theophylline in varying quantities. Some studies have suggested that the caffeine content of guarana $(40-80 \mathrm{mg}$ per gram of extract) is not always declared in packaging and is additional to the listed caffeine content of energy drinks. ${ }^{8}$ Hence, the caffeine dose may be higher than that listed on the beverage ingredients list. However, Australian Food Standards Code 2.6.4 requires labelling of the total amount of caffeine from all sources, pure and naturally occurring. ${ }^{12}$ Guarana is currently thought to have no adverse effects other than potential caffeine toxicity. ${ }^{13}$ Similarly, taurine, an amino acid found in many energy drinks, is purportedly inotropic, and considered to be non-toxic at typical doses. Ginseng, a herbal extract famous for its purported stimulant and aphrodisiac properties, is present in energy drinks below common daily doses, and has not been reported to be toxic. Ginseng, however, has multiple and important drug interactions that may become clinically relevant depending on the amount of ginseng ingested and the dose and frequency of the drugs that might interact with it. ${ }^{14}$

Even as little as $50 \mathrm{mg}$ of caffeine can induce tachycardia and agitation. In overdose, caffeine toxicity can mimic amphetamine poisoning and lead to seizures, psychosis, cardiac

4 Frequency of the most commonly reported symptoms, by type of exposure and co-ingestant use $(n=202)$

\begin{tabular}{lccc}
\cline { 2 - 3 } Symptom & $\begin{array}{c}\text { Rocreational ingestion }(n=188) \\
(n=117)\end{array}$ & $\begin{array}{c}\text { Alcohol or other } \\
\text { caffeinated } \\
\text { co-ingestant }(n=71)\end{array}$ & $\begin{array}{c}\text { Accidental } \\
\text { paediatric ingestion } \\
(n=14)\end{array}$ \\
\hline Palpitations/tachycardia & 33 & 22 & 2 \\
Tremor/shaking & 30 & 21 & 0 \\
Agitation/restlessness & 29 & 22 & 9 \\
Gastrointestinal upset & 29 & 29 & 4 \\
Chest pain/schaemia & 6 & 8 & 0 \\
Dizziness/syncope & 6 & 9 & 0 \\
Paraesthesia & 6 & 3 & 1 \\
Insomnia & 5 & 3 & 0 \\
Respiratory distress & 5 & 5 & 1
\end{tabular}

arrhythmias and, potentially but rarely, death. ${ }^{15-20}$ In 2009, a caffeinerelated death from energy drinks was reported. ${ }^{21}$ Electrocardiograms showed that the patient had acute myocardial ischaemia that was probably brought on by caffeine-induced coronary vasospasm. It has been postulated that the pathophysiology of such coronary events involves increased platelet aggregation and reduced endothelial functionality. ${ }^{22}$

In our study, calls regarding toxicity from energy drinks fell into a bimodal distribution: accidental ingestion in young children, and recreational use in adolescents. It is concerning that the trend of misuse and toxicity appears to be increasing among teenagers and that the number of energy drink units ingested far exceeds recommended maximum levels. Some manufacturers suggest $200 \mathrm{mg}$ /day of caffeine as a maximum, which equates to roughly one and a quarter $500 \mathrm{~mL}$ cans of energy drink. The variety of symptoms reported in our study was consistent with caffeine overdose and, potentially, stimulant misuse. Nearly $60 \%$ of calls reporting recreational use came from EDs, suggesting that hospitalisation is warranted in a significant proportion of cases. Although it occurred in a minority of subjects, serious toxicity leading to cardiac complications (coronary ischaemia, arrhythmias) and neurological complications (hallucinations, psychosis, seizures) is of grave concern both to the community and clinicians.

Studies among American college students called attention to the mix- ing of energy drinks with alcohol., ${ }^{3,23}$ Young people, particularly adolescents, appear to be least concerned with this dangerous phenomenon. ${ }^{4,24}$ This was evident in our results, in that almost one-quarter of calls reporting recreational consumption involved co-ingestion of alcohol. Nearly 30\% of calls involved co-ingestion of caffeine tablets or other stimulants such as amphetamines. This suggests that knowledge of energy drink effects and toxicity is poor, and mixing of substances is not seen as a problem in this cohort of adolescents and young adults.

Data on caffeine-related toxicity have been reported from poison centres in the United Kingdom and United States. ${ }^{17,25}$ We are not aware of other studies specifically reporting poison control centre data on toxicity from energy drinks. However, misuse by adolescents of caffeine in nonprescription medication as well as in energy drinks has been commonly reported to regional poison centres in the US. ${ }^{26}$ Even more alarming is the practice of combining caffeine misuse with other pharmaceuticals, which has been associated with admission to hospital. ${ }^{27}$ A 1999 Australian survey of NSW school children aged 8-18 years found that energy drink consumption was more prevalent in boys and increased with age in girls. ${ }^{28}$

Limitations of our retrospective analysis include the non-standardised methods of telephone enquiry and coding that are likely to have resulted in underreporting of exposures, $\mathrm{CO}^{-}$ ingestants and symptoms. We did not analyse outcomes for subjects who 
were hospitalised. As the NSWPIC takes roughly $50 \%$ of all poisonsrelated calls in Australia, our results may only partially reflect national trends. With increased call-load sharing between the NSWPIC and other Australian poisons centres, the number of after-hours calls to the NSWPIC has decreased by roughly $20 \%$ since 2009 . This is also reflected in the drop in the number of calls related to caffeinated energy drinks by a similar percentage in 2010.

Given the clear evidence of toxicity and the growing number of hospitalisations associated with consumption of energy drinks, particularly in a vulnerable adolescent population, health authorities should increase awareness of the problem, improve package labelling and regulate caffeine content. We recommend that labelling and any marketing of these products should include appropriate health warnings and the national poisons hotline number (13 1126 in Australia). Energy drinks are marketed for similar effects and should carry similar warning labels as non-prescription, over-the-counter caffeine tablets. The regulation of caffeinated energy drinks is currently under consideration by the Australia and New Zealand Food Regulation Ministerial Council. ${ }^{29}$ This review and regulation is timely and essential.

Competing interests: No relevant disclosures.

Received 4 Jul 2011, accepted 15 Nov 2011.
1 AC Nielsen. Nielsen convenience report, 2008. http://au.nielsen.com/site/documents/ ConvenienceReport2008-extob.pdf (accessed Mar 2011).

2 Higgins JP, Tuttle TD, Higgins CL. Energy beverages: content and safety. Mayo Clin Proc 2010; 85: 1033-1041.

3 Malinauskas BM, Aeby VG, Overton RF, et al. A survey of energy drink consumption patterns among college students. Nutr J 2007; 6: 35.

4 Arria AM, Caldeira KM, Kasperski SJ, et al. Energy drink consumption and increased risk for alcohol dependence. Alcohol Clin Exp Res 2011; 35: 365375.

5 Attila S, Cakir B. Energy-drink consumption in college students and associated factors. Nutrition 2011; 27: 316-322.

6 Riddell L, Keast RS. Is caffeine in soft drinks really necessary [letter]? Med J Aust 2007; 187: 655.

7 Reissig CJ, Strain EC, Griffiths RR. Caffeinated energy drinks - a growing problem. Drug Alcohol Depend 2009; 99: 1-10.

8 Seifert SM, Schaechter JL, Hershorin ER, et al. Health effects of energy drinks on children, adolescents, and young adults. Pediatrics 2011 127: 511-528.

9 AC Nielsen. Nielsen convenience and impulse report, 2010. http://au.nielsen.com/site/ documents/NielsenConvenience ReportJune2010LR.pdf (accessed Mar 2011).

10 Red Bull Australia. Red bull products. http:// www.redbull.com.au/cs/Satellite/en_AU/RedBull-Australia/Products/011242758640967 (accessed Feb 2011).

11 Pennay A, Lubman DI, Miller P. Combining energy drinks and alcohol - a recipe for trouble? Aust Fam Physician 2011; 40: 104-107.

12 Food Standards Australia New Zealand. Australia New Zealand Food Standards Code - Standard 2.6.4 (2009): formulated caffeinated beverages. http://www.comlaw.gov.au/Details/ F2009C00814 (accessed Nov 2011).

13 Duchan E, Patel ND, Feucht C. Energy drinks: a review of use and safety for athletes. Phys Sportsmed 2010; 38: 171-179.

14 Hu Z, Yang X, Ho PC, et al. Herb-drug interactions: a literature review. Drugs 2005; 65: 1239-1282.

15 McGee MB. Caffeine poisoning in a 19-year-old female. J Forensic Sci 1980; 25: 29-32.

16 Benowitz NL, Osterloh J, Goldschlager N, et al. Massive catecholamine release from caffeine poisoning. JAMA 1982; 248: 1097-1098.
17 Shum S, Seale C, Hathaway D, et al. Acute caffeine ingestion fatalities: management issues. Vet Hum Toxicol 1997; 39: 228-230.

18 Di Rocco JR, During A, Morelli PJ, et al. Atrial fibrillation in healthy adolescents after highly caffeinated beverage consumption: two case reports. J Med Case Reports 2011; 5: 18.

19 Cannon ME, Cooke CT, McCarthy JS. Caffeineinduced cardiac arrhythmia: an unrecognised danger of healthfood products. Med J Aust 2001; 174: 520-521.

20 Menkes DB. Transient psychotic relapse temporally related to ingestion of an "energy drink" [letter]. Med J Aust 2011; 194: 206.

21 Berger AJ, Alford K. Cardiac arrest in a young man following excess consumption of caffeinated "energy drinks". Med J Aust 2009; 190: 41-43.

22 Worthley Ml, Prabhu A, De Sciscio P, et al. Detrimental effects of energy drink consumption on platelet and endothelial function. Am J Med 2010; 123: 184-187.

23 O'Brien MC, McCoy TP, Rhodes SD, et al. Caffeinated cocktails: energy drink consumption, high-risk drinking, and alcohol-related consequences among college students. Acad Emerg Med 2008; 15: 453-460.

24 Kaminer Y. Problematic use of energy drinks by adolescents. Child Adolesc Psychiatr Clin N Am 2010; 19: 643-650.

25 Waring WS, Laing WJ, Good AM, et al. Acute caffeine ingestion: clinical features in patients attending the emergency department and Scottish poison centre enquiries between 2000 and 2008. Scott Med J 2009; 54: 3-6.

26 Crouch BI, Caravati EM, Booth J. Trends in child and teen nonprescription drug abuse reported to a regional poison control center. Am J Health Syst Pharm 2004; 61: 1252-1257.

27 McCarthy DM, Mycyk MB, DesLauriers CA Hospitalization for caffeine abuse is associated with abuse of other pharmaceutical products. Am J Emerg Med 2008; 26: 799-802.

28 O'Dea J, Rawstorne P. Consumption of dietary supplements and energy drinks by school children. Med J Aust 2000; 173: 389.

29 The Australia and New Zealand Food Regulation Ministerial Council. Food Ministers briefed on progress of historic Food Labelling Review. http:/ /www.health.gov.au/internet/main/ publishing nsf/Content/foodsecretariatcommuniques-031210 (accessed Jun 2011). 